\title{
Left Bundle Branch Block, an Old-New Entity
}

\author{
Günter Breithardt • Ole-Alexander Breithardt
}

Received: 19 December 2011 / Accepted: 21 December 2011 /Published online: 19 January 2012

(C) The Author(s) 2012. This article is published with open access at Springerlink.com

\begin{abstract}
Left bundle branch block (LBBB) is generally associated with a poorer prognosis in comparison to normal intraventricular conduction, but also in comparison to right bundle branch block which is generally considered to be benign in the absence of an underlying cardiac disorder like congenital heart disease. LBBB may be the first manifestation of a more diffuse myocardial disease. The typical surface ECG feature of LBBB is a prolongation of QRS above $0.11 \mathrm{~s}$ in combination with a delay of the intrinsic deflection in leads V5 and V6 of more than $60 \mathrm{~ms}$ and no septal $\mathrm{q}$ waves in leads I, V5, and V6 due to the abnormal septal activation from right to left. LBBB may induce abnormalities in left ventricular performance due to abnormal asynchronous contraction patterns which can be compensated by biventricular pacing (resynchronization therapy). Asynchronous electrical activation of the ventricles causes regional differences in workload which may lead to asymmetric hypertrophy and left ventricular dilatation, especially due to increased wall mass in late-activated regions, which may
\end{abstract}

This article is partly based on a previous publication by G. Breithardt et al. [1].

G. Breithardt $(\bowtie)$

Department of Cardiology and Angiology,

Hospital of the University of Münster,

Albert-Schweitzer-Campus 1, Gebäude A1,

48149 Münster, Germany

e-mail: g.breithardt@uni-muenster.de

O.-A. Breithardt

Department of Cardiology and Angiology, Medizinische Klinik 2,

University Hospital Erlangen,

Erlangen, Germany

O.-A. Breithardt

Department of Electrophysiology, Heart Center Leipzig,

Leipzig, Germany aggravate preexisting left ventricular pumping performance or even induce it. Of special interest are patients with LBBB and normal left ventricular dimensions and normal ejection fraction at rest but who may present with an abnormal increase in pulmonary artery pressure during exercise, production of lactate during high-rate pacing, signs of ischemia on myocardial scintigrams (but no coronary artery narrowing), and abnormal ultrastructural findings on myocardial biopsy. For this entity, the term latent cardiomyopathy had been suggested previously.

Keywords Left bundle branch block · Dyssynchrony · Heart failure $\cdot$ Left ventricular dyssynchrony $\cdot$ Mechanisms

\section{Introduction}

The purpose of this manuscript is to present an overview on some clinical and pathophysiological aspects of left bundle branch block (LBBB) that appear important to us and that are based partly on early studies and observations which also remain relevant several decades later. However, the purpose is not to present a complete review of the vast literature on intraventricular conduction disturbances which has exploded during the recent decade. Most of this will be dealt with elsewhere in this issue of the journal.

\section{Left Ventricular Systolic Failure and Left Bundle Branch Block}

Left ventricular systolic failure has traditionally been attributed to left ventricular remodeling due to intrinsic abnormalities of myocyte function and subsequent derangements in neurohumoral activation. Only during the recent decade, 
abnormalities in left ventricular performance due to abnormal activation patterns have gained more widespread attention in the cardiology literature and in clinical practice. This very recent interest has mainly been stimulated by the very successful introduction of cardiac resynchronization therapy (CRT) as a new, device-based treatment option for patients with end-stage heart failure and ventricular conduction delays in the mid-1990s [2, 3]. Several randomized clinical trials have now shown its beneficial potential in patients with chronic heart failure $[4,5]$. However, the initial observations on the negative consequences of abnormal electrical ventricular activation on mechanical cardiac performance date back much earlier and were first described already soon after the introduction of invasive and non-invasive imaging techniques into clinical cardiology [6]. These early studies described how the abnormal and/or delayed left ventricular activation wave front could lead to a reduction in left ventricular efficiency and performance which is largely independent of myocyte contractile function (Table 1) [6-8]. Abnormal motion of the interventricular septum in LBBB was first demonstrated echocardiographically by McDonald [9]. During early systole, at the time of aortic valve opening, the interventricular septum demonstrates a dorsal (posterior) motion, the extent of which may vary considerably ("septal beak") and which is followed by abnormal anterior motion later during the ejection phase. Subsequently, Fujii et al. [10] described three patterns of septal motion in 37 patients with LBBB: Types A and B presented early and abrupt posteriorly directed motion of the septum during the pre-ejection period after which the septum moved anteriorly in type A and posteriorly in type B. Type C exhibited akinetic or dyskinetic septal motion throughout systole. The onset of posterior wall contraction was delayed in all patients with complete left bundle branch block.

In a series of 100 cases, Curtius et al. [8] discerned three types of septal motion during meso- and late systole: anterior (paradox) in $18 \%$ of cases (type A), posterior (normal) in $58 \%$ (type B), and intermediate (type AB) in $24 \%$ of cases. Patients with anterior (paradox) movement during meso- and late systole (group A) had more severe clinical disease than did patients in group B. Their ECG showed a longer QRS complex. On X-ray, their cardiothoracic ratio was larger, and on M-mode echocardiography, they had larger LV end-diastolic diameters. Mean values of septal movement of patients with an intermediate pattern during meso- and late systole fell between those with an anterior (paradox) and those with a normal pattern. Left ventricular ejection fraction (LVEF) was lower in patients with anterior (paradox) than in those with intermediate or normal mesoand late systolic contraction. Mean pulmonary artery pressure during exercise was higher in patients with anterior (paradox) movement than in those with intermediate or normal contraction [8]. Based on these observations, it was assumed that in patients with normal meso- and late systolic movement, the block is more peripherally located than in those with anterior movement.

Asynchronous electrical activation of the ventricles causes regional differences in workload which may lead to asymmetric hypertrophy and LV dilatation, especially due to increased wall mass in late-activated regions [11]. In hypertrophic hearts, chronic pacing at the RV apex suppressed the development of hypertrophy in the early activated apical septum but did not cause additional hypertrophy in late-activated regions [12].

In order to resynchronize left ventricular contraction, Curtius et al. [7] mentioned that an abnormal contraction pattern in LBBB might be reversed by pacing. It took more than a decade before this theoretical concept was realized: In 1994, Bakker et al. [2] and Cazeau et al. [3] were the first to demonstrate independently from each other in humans that synchronized ventricular pacing targeted to the site of latest electrical activation has the potential to compensate for abnormal left ventricular activation and may improve global ventricular function by resynchronization of dyssynchronously contracting myocardium.

Based on the inclusion criteria of the major randomized trials, the present heart failure and pacing guidelines consider CRT as a class I indication for patients with symptomatic
Table 1 Abnormal findings in patients with left bundle branch block and normal left ventricular function at rest

\begin{tabular}{lll}
\hline Abnormality & Technique & Reference \\
\hline $\begin{array}{l}\text { Ischemia in LBBB } \\
\begin{array}{l}\text { Nonspecific morphological alterations } \\
\text { in left bundle branch block }\end{array}\end{array}$ & $\begin{array}{l}\text { Scintigraphy; cardiac lactate metabolism } \\
\text { Endomyocardial catheter biopsy }\end{array}$ & {$[1,46,70]$} \\
$\begin{array}{l}\text { Abnormal increase in pulmonary artery } \\
\text { pressure during exercise in the presence } \\
\text { of normal ejection fraction }\end{array}$ & $\begin{array}{l}\text { Hemodynamic study (Swan-Ganz } \\
\text { procedure) }\end{array}$ & {$[46,72,73]$} \\
$\begin{array}{l}\text { Wall motion analysis in LBBB: } \\
\begin{array}{l}\text { Abnormal } \\
\text { motion of the interventricular septum }\end{array}\end{array}$ & Echocardiography & {$[46,61,73,78]$} \\
$\begin{array}{l}\text { Mitral regurgitation in LBBB } \\
\text { Wall motion analysis in LBBB: } \\
\text { interventricular delay }\end{array}$ & Echocardiography & {$[6-10]$} \\
\hline
\end{tabular}


systolic heart failure and QRS prolongation of $0.12 \mathrm{~s}$ or greater [13, 14], but do not consider QRS morphology (i.e., type of bundle branch block) for patient selection. In the Comparison of Medical Therapy, Pacing, and Defibrillation in Heart Failure trial [4], patients without a LBBB pattern did not show a statistically significant benefit compared to those with LBBB, and those with QRS durations $\leq 0.147$ s had no benefit as well.

The renewed interest in the significance of the type of intraventricular conduction disturbance such as classical LBBB came from the recent observation in Multicenter Automatic Defibrillator Implantation Trial-Cardiac Resynchronization Therapy that the benefit of CRT in class I and II heart failure patients was confined to those who had classical complete LBBB whereas those with a non-LBBB configuration did not derive any benefit [15]. This is further supported by a recent report from the Medicare Implantable Cardioverter-Defibrillator Registry on 14,946 patients who had received CRT and met standard QRS and LVEF criteria for CRT implantation [16]. Among these patients, 10,356 (69\%) had LBBB, 1,638 (11\%) had right bundle branch block, and 2,952 (20\%) had a nonspecific intraventricular conduction disturbance. During a median follow-up of 40 months, patients without LBBB had significantly increased early and late mortality compared to patients with LBBB since a positive response to CRT will mostly be confined to those with LBBB. A QRS duration $\geq 0.150$ s predicted more favorable outcomes in LBBB but not in right bundle branch block.

\section{Electrocardiographic Definition of LBBB}

Due to the increased importance of separating LBBB from diffuse intraventricular conduction disturbances, a look at the ECG criteria is warranted. In classical LBBB (Fig. 1), the dominant feature of intraventricular block is the prolonged QRS complex ( $\geq 0.12 \mathrm{~s}$ ) due to delayed activation of the left ventricle, accompanied by a characteristic morphology of the QRS complex [17-19]. Besides conduction disturbances in the specific parts of the intraventricular conduction system (classical LBBB), a diffuse intraventricular conduction disturbance may exist in the left ventricle due to more peripherally located, regional conduction disturbances (e.g., postmyocardial infarction). Such a nonspecific intraventricular conduction defect also presents with a QRS interval prolongation of $0.12 \mathrm{~s}$ or more but with a pattern of QRS that does not correspond to the classical pattern of left (or right) bundle branch block. It should be noted that the term block does not necessarily imply a complete interruption of conduction but may be due to major delay of conduction in some parts of the conduction system which explains the variety of morphologies that can be observed and the frequently nonspecific patterns of conduction delay [20].

Besides the typical prolongation of QRS above $0.11 \mathrm{~s}$, there is a delay of the intrinsic deflection in leads V5 and V6 of more than $60 \mathrm{~ms}$, and there are typically no septal $\mathrm{q}$ waves in leads I, V5, and V6 due to the abnormal septal activation from right to left. A narrow q wave may be present in lead aVL in the absence of myocardial pathology, and broad notched or slurred $\mathrm{R}$ waves can be observed in the left-sided leads I, aVL, V5, and V6. The activation wave front from the right ventricle proceeds slowly across the septum toward the late-activated left ventricular posterolateral segments and consequently the right-sided chest leads $\mathrm{V} 1$ and V2 present with an $\mathrm{rS}$ or QS pattern. The ST and T wave vector is $180^{\circ}$ discordant to the QRS vector.

Recently, Strauss et al. stressed the importance of notched or slurred $\mathrm{R}$ waves in left-sided leads $\mathrm{I}$, aVL, $\mathrm{V} 5$, or V6 as a classical feature of LBBB [21]. These notches represent different moments during left ventricular

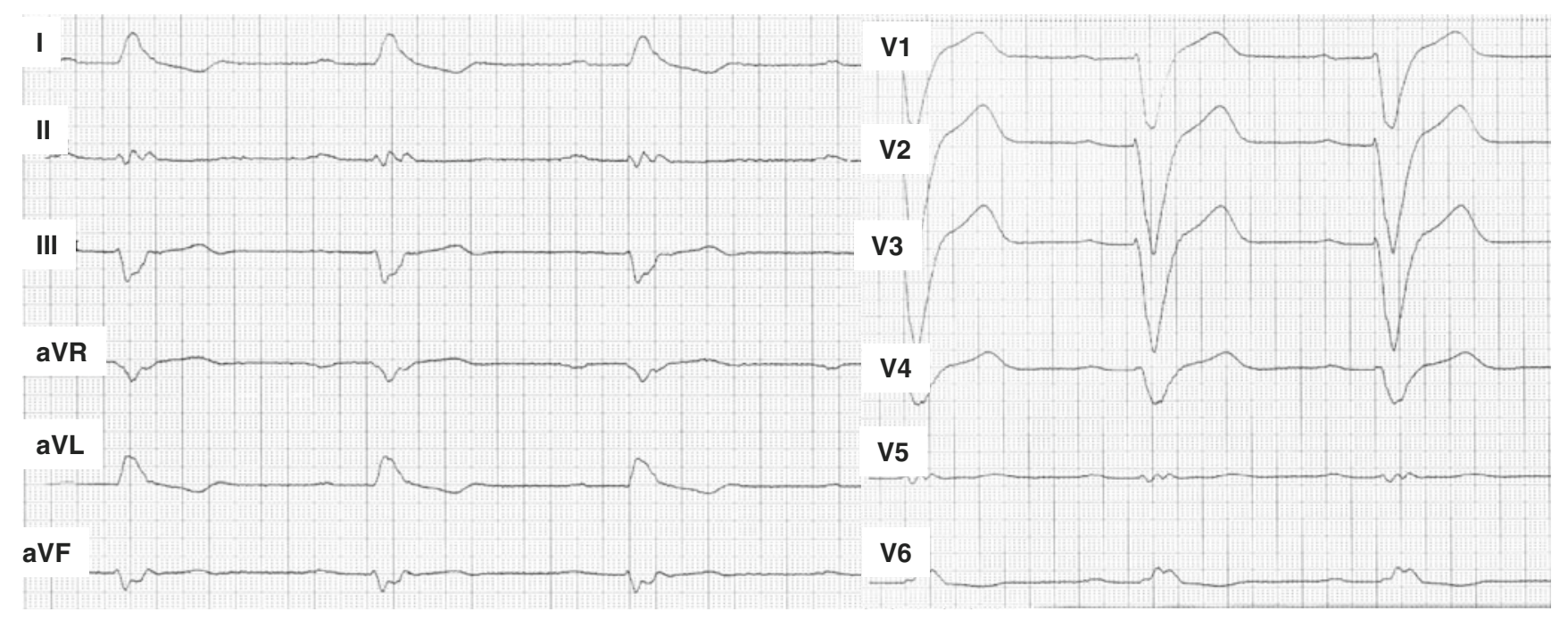

Fig. 1 An example of classical left bundle branch block in a patient with heart failure due to dilated cardiomyopathy 
activation as determined by computer simulation of LBBB [22]. According to their explanation, the first notch (depicted at $50 \mathrm{~ms}$ after QRS onset) represents the time when the electrical depolarization wave front reaches the endocardium of the left ventricle after proceeding through the septum. The second notch then occurs when the depolarization wave front begins to reach the epicardium of the posterolateral wall. They explain the slurring of QRS, with little change in QRS amplitude between the two notches, by the fact that the magnitude and direction of the mean electrical vector remains approximately constant once depolarization reaches the endocardium of the left ventricle because it has to proceed outward in the septum and around the left ventricle to the posterolateral free wall [21]. In typical LBBB, the site of block (or major conduction delay) may vary. It may be located in the main bundle or the distal conduction system, but even longitudinal dissociation with asynchronous conduction in the bundle of His may give rise to abnormal patterns of activation within the bundle of His since specific fibers appear to be predestined to activate certain parts of the right and left ventricles.

The same group very recently also questioned the current definition of complete LBBB and proposed stricter criteria for the diagnosis, especially with regard to improving the identification of suitable heart failure patients for cardiac resynchronization therapy [21] (Table 2). They rightly criticize that besides an increase in QRS duration above normal, QRS morphology frequently has not been considered carefully enough. They also point out that the threshold of $0.12 \mathrm{~s}$ was established on the basis of comparing the ECG in humans to those in dogs and suggest that the lower cutoff for complete LBBB should rather be $\geq 0.14 \mathrm{~s}$ in men and $\geq 0.13 \mathrm{~s}$ in women. A higher QRS cutoff for men was proposed because of the larger heart size which takes longer to depolarize. In normal conduction, the mean QRS duration is $92.7 \pm 9.3 \mathrm{~ms}$ for men and $87.1 \pm 8.7 \mathrm{~ms}$ for women [23]. The absence of septal Q waves has generally been considered as another typical criterion for classical LBBB. However, since an anterior apical infarct can lead to $\mathrm{Q}$ waves in these leads in the presence of LBBB, Strauss et al. suggested that the presence of $\mathrm{Q}$ waves in leads I, V5, and V6 should not exclude patients from a diagnosis of LBBB [21].

Table 2 Proposed renewed criteria for diagnosing LBBB [21]

Criteria for complete LBBB

QRS duration $\geq 140 \mathrm{~ms}$ (men) or $\geq 130 \mathrm{~ms}$ (women)

QS or rS in leads V1 and V2

Mid-QRS notching or slurring in $\geq 2$ of leads V1, V2, V5, V6, I, and aVL

\section{Electrophysiological Characterization of Intraventricular Conduction in LBBB}

In many patients with bundle branch block, bundle of His recordings has revealed abnormal atrioventricular conduction properties, especially within the His-Purkinje system. The mean H-V interval in patients with LBBB was significantly longer than in patients with right bundle branch block $[24,25]$. In LBBB, the activation of the septum from the right side occurs with only a minimal delay of a few milliseconds [26-29]. Thus, a marked prolongation of the H-V interval in LBBB should be considered to be due to an additional conduction delay within the bundle of His or the right bundle branch, indicating truncular or trifascicular disease [30-33]. In nearly all patients with LBBB and prolonged $\mathrm{H}-\mathrm{V}$ interval, a delay is seen between the first recorded septal activation ( $\mathrm{V}$ wave on intracardiac recordings) and the activation of the RV apex which underscores this interpretation [25]. The occurrence of block within the left bundle branch does not necessarily prolong $\mathrm{H}-\mathrm{V}$ time because in patients with intermittent LBBB, the $\mathrm{H}-\mathrm{V}$ interval remains constant [34].

The etiology of LBBB plays a role in determining the H$\mathrm{V}$ interval. Nearly all patients with congestive (dilated) cardiomyopathy exhibited a prolonged $\mathrm{H}-\mathrm{V}$ interval whereas in other groups, both normal and abnormal values occurred [25]. The abnormal morphological findings in the RV myocardium discussed elsewhere in this paper suggest that both the conduction system and the ordinary myocardium are involved in the same pathological process.

As far as left ventricular hemodynamic performance is concerned, the speed and spread of left ventricular activation may be important. Catheter mapping studies by the group of Mark Josephson assessed endocardial ventricular activation in 18 patients with LBBB [35]. Four patients had no organic heart disease, six had congestive cardiomyopathy, and eight had coronary artery disease and previous infarction. Twelve patients had one septal site of left ventricular endocardial breakthrough whereas six had two left ventricular endocardial breakthrough sites, with one site always being septal which would suggest that these patients did not have complete LBBB. Total left ventricular endocardial activation time was significantly longer in patients with coronary artery disease and previous infarction $(119 \mathrm{~ms})$ than in those without organic heart disease $(81 \mathrm{~ms} ; P<0.05)$ and in patients with congestive cardiomyopathies $(61 \mathrm{~ms} ; P<0.001)$. Duration of total right ventricular endocardial activation was $36 \mathrm{~ms}$ (seven patients). The final site of right ventricular activation was at $44 \mathrm{~ms}$ after the onset of the QRS complex. In a subsequent study from the same group, Vassallo et al. performed endocardial mapping in 40 patients during right ventricular pacing [36]. Thirtynine of 40 patients had only a single left ventricular 
breakthrough site representing the pattern of LBBB which was located on the midseptum in 33 , the apical septum in 4 , and the basal septum in 2 .

Later, A. Auricchio et al. [20] used more sophisticated and novel 3D contact and noncontact mapping systems to study the sequence of left ventricular activation in 24 patients with heart failure and LBBB QRS morphology during intrinsic rhythm and asynchronous pacing simultaneously. They could demonstrate that a U-shaped conduction pattern was imposed on the activation sequence of the left ventricle by a transmural functional line of block located between the left ventricular septum and the lateral wall with a prolonged activation time. Patients with LBBB QRS morphology, independent of the duration of the QRS complex, may have an anterior, lateral, or inferior line of block which points to a remarkable heterogeneity of LBBB. This correlated with echocardiographic observations of variable regions of mechanical delay in patients selected for cardiac resynchronization therapy [37-40].

\section{LBBB as Indicator of Left Ventricular Dysfunction and Progression of Heart Failure}

It has been known for long time that LBBB is generally associated with a poorer prognosis in comparison to normal conduction but also in comparison to right bundle branch block which is generally considered to be benign in the absence of an underlying cardiac disorder like congenital heart disease. Early studies reported a mean survival of less than 5 years after documentation of LBBB [41, 42]. However, a few patients with LBBB appear to have a good prognosis which does not differ from that of patients with right bundle branch block [42-45]. LBBB may occur in asymptomatic individuals, patients with extensive myocardial infarction, and in those with heart failure, especially in dilated, non-ischemic cardiomyopathies. In some patients, LBBB (sometimes rate dependent) may be the first manifestation of heart disease whereas the clinical presentation of a dilated cardiomyopathy develops only some years later [46-49]. Early studies reported a mean survival of less than 5 years after documentation of LBBB $[41,50]$.

In patients with dilated cardiomyopathy, a progressive increase in QRS duration and the presence of a LBBB pattern were related to disease progression [47]. In 14 of 18 patients with congestive (dilated) cardiomyopathy, progression of disease was accompanied by a movement of the QRS frontal plane vector from a normal axis to left axis deviation which mainly occurred during the first 2 years after clinical manifestation of cardiomyopathy. It has previously been shown that QRS duration increases with progressive dilatation of the left ventricle, e.g., in patients with aortic valve disease [51]. In a series of necropsy-proven idiopathic dilated cardiomyopathy, patients with multiple ECGs before death also showed a progressive increase in QRS duration [52] similar to our previous report [47]. More recently, the relationship between QRS duration and left ventricular mass and volume was studied by Stewart et al. [53] in a substudy of the Ongoing Telmisartan Alone and in Combination with Ramipril Global Endpoint Trial/Telmisartan Randomised Assessment Study in ACE Intolerant Subjects with Cardiovascular Disease clinical trials. Three hundred sixty-eight patients had a cardiac magnetic resonance scan to measure left ventricular mass, end-systolic volume, end-diastolic volume, and ejection fraction at baseline and after 2 years of follow-up. Each 10-ms increase in QRS duration both within and above the normal reference range was associated with an $8.3 \%$ increase in left ventricular mass, a 9.2\% increase in end-diastolic volume, and a $7.8 \%$ increase in end-systolic volume. From the prognostic point of view, increased QRS duration in patients with heart failure has been shown by several studies to be correlated to a poor prognosis [54]. The progressive increase in PR, QRS, and QT intervals is more pronounced in patients with dilated cardiomyopathy who die and progressive QRS widening independently and unfavorably predicts cardiac death or the need for heart transplantation $[55,56]$.

A human experiment with induction of LBBB as one of its unwanted effects is represented by transcatheter aortic valve implantation (TAVI) which allows exact timing of the onset of LBBB. TAVI is an effective therapy in selected patients with severe, symptomatic aortic stenosis. However, up to $30 \%$ to $50 \%$ of patients develop a LBBB as a direct effect of valve implantation depending on the type of implanted prosthesis. The prognostic impact of the induction of LBBB was recently reported from a multicenter Dutch registry encompassing all patients who underwent TAVI between November 2005 and December 2010 [57]. All-cause mortality during long-term follow-up after TAVI was significantly higher in patients who developed LBBB $(37.1 \% ; n=86)$, as compared with patients who did not develop LBBB (23.3\%; $n=103 ; P=0.002)$. By multivariate regression analysis, TAVI-induced LBBB was the strongest independent predictor of mortality at follow-up. These data confirm the negative prognostic impact of disturbances in conduction and, thus, ventricular performance on outcomes.

\section{LBBB as a Sign of Dyssynchrony}

As already discussed above, QRS prolongation in LBBB has for long been known to cause abnormal ventricular contraction patterns with depressed ejection fraction and to be inversely related to hemodynamic performance. In a patient with intermittent LBBB, deterioration of left ventricular performance occurred during LBBB [58]. Das et al. 
[59] also reported that QRS duration has a significant inverse relationship with ejection fraction and that prolongation of QRS duration ( $\geq 0.170 \mathrm{~s}$ ) in the presence of LBBB is a marker of significant left ventricular systolic dysfunction. The link between LBBB and reduced performance of left ventricular pump function due to dyssynchrony is now well established. These findings have established the basis of cardiac resynchronization therapy.

The time delay between the upslope of the left and right ventricular pressure signals is a reliable measure of mechanical interventricular asynchrony which adds valuable information concerning the nature of asynchronous activation of the ventricles [60]. These data show that right ventricular activation occurs before initiation of left ventricular activation in patients with LBBB. Left ventricular endocardial activation in patients with LBBB occurs as a result of right-to-left trans-septal activation, and the left ventricular endocardial activation sequence in patients with LBBB is heterogeneous (see above). Patients with coronary artery disease and LBBB have significantly longer total left ventricular endocardial activation times than do patients with no organic heart disease or those with congestive cardiomyopathies. Delay of trans-septal activation is common to all forms of LBBB, but the type of heart disease markedly influences the subsequent pattern of left ventricular activation; patients with prior myocardial infarctions have longer left ventricular activation times than do those without apparent heart disease or cardiomyopathy.

Since patients with LBBB often complain of exertional dyspnea despite normal left ventricular dimensions and function at rest, data from exercise tests may help to explain these symptoms by an abnormal hemodynamic response (Table 1). Among 51 patients with LBBB and normal echocardiograms, coronary angiograms, and ventriculograms, 29 patients showed an abnormal increase in mean pulmonary artery pressure during exercise, which exceeded the upper limit of normal of $30 \mathrm{mmHg}$ [61]. Therefore, despite angiographically normal coronary arteries and normal echocardiograms and ventriculograms, a generalized myocardial disorder and/or cardiac ischemia (see below) was suspected to be present during exercise since these patients have latent or provocable impairment in LV function.

Intraventricular conduction delays in the presence of a dilated left ventricle may favor the development of mitral regurgitation [62] and may thereby aggravate heart failure (Table 1). Clinical and experimental observations suggest that a regional wall motion abnormality can induce functional mitral regurgitation. The primary cause of this regurgitation is not regional dysfunction per se but rather geometric changes in the left ventricle and of mitral valve attachment [63-65]. Functional mitral regurgitation is strongly related to changes in the three-dimensional geometry of the mitral valve attachments. This has practical implications for attempts to restore a more favorable configuration that reduces or eliminates regurgitation [66]. Repair of the mitral valve may, therefore, be an alternative to heart transplantation as a means of improving LV performance, even in the presence of severe left ventricular myocardial dysfunction.

\section{Ischemia in LBBB}

Metabolic studies have shown that LBBB may be related to the presence of myocardial ischemia. In 95 patients with abnormal ECGs [61], an abnormal decrease in arteriocoronary venous difference of lactate concentration (i.e., the production of lactate by the myocardium) during high-rate pacing was used to detect myocardial ischemia. In 51 patients with LBBB, normal ejection fraction, absence of coronary artery disease, and no history of hypertension, the decrease in the arteriocoronary venous lactate concentration was slightly less pronounced than in patients with significant coronary artery narrowing on coronary angiography, but it was still more pronounced than in patients with (only) ST segment depression. Myocardial scintigrams were abnormal in all four patients with LBBB in whom scintigraphy had been performed (Table 1).

Exercise-induced myocardial perfusion defects which may suggest myocardial ischemia as well have been reported in anteroapical and anteroseptal areas in patients with complete LBBB and angiographically normal coronary arteries [67, 68]. In an experimental study, Hirzel et al. suggested that right ventricular pacing diminished septal myocardial blood flow because of abnormal sequence of electrical ventricular depolarization, as evidenced by septal defects in myocardial scintigrams [69]. Vernooy et al. [70] also suggested that asynchronous ventricular activation during LBBB leads to redistribution of circumferential shortening and myocardial blood flow and, in the long run, left ventricular remodeling. Septal hypoperfusion during LBBB appeared to be primarily determined by reduced septal workload which would not explain the abovementioned findings of lactate global production by the left ventricle. Wackers et al. [71] compared regional myocardial uptake of thallium-201 during rapid atrial pacing (simulating normal conduction) with that during rapid right ventricular pacing (simulating LBBB). No significant quantitative difference was observed in regional thallium-201 uptake. Contrary to Hirzel et al., Wackers et al. concluded that the altered sequence of ventricular depolarization itself was not the main cause for myocardial perfusion defects in LBBB which would fit with the hypothesis that there is an underlying generalized myocardial abnormality which would explain the output of lactate in the coronary sinus [61]. 


\section{Morphological Alterations in LBBB}

Myocardial biopsy specimen from the right ventricular septum revealed abnormal findings in all but one of 28 patients (EF 72 $\pm 10.4 \%$ ) with LBBB [72, 73]. These findings support the concept of a diffuse myocardial disease in such cases which, therefore, were classified as latent cardiomyopathy (LCM; see below). There was no evidence for small vessel disease. Semiquantitative ultrastructural evaluation of RV myocardial biopsies in patients with LBBB and normal left ventricles showed abnormal findings in ten of 21 cases [72, 73].

From the morphological point of view, the ultrastructural alterations on biopsy in patients with dilative cardiomyopathy (previously classified as congestive cardiomyopathy) differed only quantitatively but not qualitatively from patients with LBBB. However, none of these changes was specific for a given clinical entity, thus representing a nonspecific response of the myocardium. Degenerative, mitochondrial, and myofibrillar changes; interstitial fibrosis; and hypertrophy of myocardial cells have all been observed, despite the presence of a normal left ventricular angiogram and absence of coronary artery disease. In some patients, these alterations were even severe as had been seen in endstage dilative cardiomyopathy. Since these morphological findings were obtained from right ventricular biopsies, a generalized myocardial disorder might be present.

\section{LBBB — Just a Conduction Disorder or a Cardiomyopathy?}

The fact that LBBB is present in certain cardiac conditions like dilative cardiomyopathy or after myocardial infarction would suggest that it is an accompanying finding which, nevertheless, may aggravate the underlying condition. However, in some cases with otherwise apparently normal hearts, LBBB appears to be the sole abnormality. In other cases, with respect to early observations from our group (G.B.) $[47,74]$ and the long-term data from Framingham [49], LBBB may be an early sign of future development of heart failure, e.g., presenting as dilated cardiomyopathy.

However, the question is whether permanent dyssynchronous activation of the left ventricle with ensuing molecular and structural remodeling may be sufficient to induce left ventricular failure or whether there is a preexisting but not yet manifest cardiomyopathy that leads to both LBBB and deterioration of left ventricular function. Besides the abovementioned example of LBBB induced by TAVI and subsequent increase in mortality (based on registry data) [57], another mechanism that mimics LBBB-like activation of the left ventricle is right ventricular pacing. The detrimental role of frequent right ventricular apical pacing has been well established [75-77]. In many cases, right ventricular apical pacing seems to be a factor contributing to aggravation of heart failure. However, there have been individual cases who were paced for long periods and who developed severe left ventricular dysfunction with low ejection fraction and elevated end-diastolic volume that was completely reversible after biventricular pacing. This would suggest that pacing alone may induce left ventricular dysfunction. One example is our first case of radiofrequency catheter ablation of the His bundle in June 1986 who developed severe heart failure after almost 20 years of permanent right ventricular pacing that was completely reversible after implantation of a biventricular pacing device within a few weeks, clinically improving already on the next day (in preparation).

\section{The Concept of a Latent Cardiomyopathy}

Kuhn et al. [46, 47] suggested that the presence of LBBB may represent an early stage of a dilative cardiomyopathy in those cases with normal left ventricular dimensions and function and normal coronary arteries at the time of initial presentation. This hypothesis was based on abnormal metabolic and hemodynamic responses as well as on the presence of ultrastructural changes on endomyocardial catheter biopsies from the right ventricular septum (see above). Based on these findings and other studies, patients with LBBB were divided into two groups, those with isolated LBBB, and those with LBBB in conjunction with such abnormal findings.

For these patients with normal left ventricular dimensions and function in whom the abnormal hemodynamic or metabolic response became evident only during exercise or in whom marked alterations of morphology were found, the term "latent cardiomyopathy" (LCM) was suggested. This latter term was proposed since these patients had abnormalities that could only be identified by specific, partly provocative, tests like exercise, myocardial biopsy, or assessment of a propensity to ischemia [46, 47].

Only limited follow-up data in such patients with LBBB and normal left ventricular dimensions and function at rest exist. Curtius et al. [74] performed a follow-up of left ventricular dimensions and function in LCM, as defined by abnormal left ventricular function during exercise and invasive measurement of hemodynamic parameters in otherwise "normal" heart. Thirty-six patients with normal left ventricular data at rest (echocardiography, left ventricular angiography, coronary angiography) but at least one pathologic functional parameter during exercise were studied prospectively by clinical means and by one- and twodimensional echocardiography (mean follow-up $3.3 \pm$ 1.3 years). No patient died and the average clinical class remained unchanged. M-mode echocardiography did not 
reveal any significant changes, neither in left ventricular end-diastolic and end-systolic dimensions nor in shortening fraction. However, in five out of nine patients with LBBB, the two-dimensional echocardiogram showed the development of a slight reduction of left ventricular contractions (without an increase in the end-diastolic dimensions). This was not observed in any patient without LBBB. Another finding was that the dimensions of the left atrium of LCM patients exceeded those of a group of normal subjects $(p<$ 0.02 ) with a further increase in the course of the disease $(p<$ 0.001 ). These results indicate that the deterioration in left ventricular function may be mechanistically related to the presence of LBBB and the accompanying abnormal left ventricular performance but that longer follow-up might be needed to develop a more pronounced clinical presentation.

\section{Conclusions}

LBBB has received much renewed attention since biventricular pacing to restore synchrony of left ventricular contraction has become a frequently used modality to treat patients with heart failure. The purpose of this retrospective view was to present some information on this entity which mostly dates back some decades but which is still relevant today and which might be a stimulus for updated research on LBBB and related disorders of intraventricular conduction disturbances.

Open Access This article is distributed under the terms of the Creative Commons Attribution Noncommercial License which permits any noncommercial use, distribution, and reproduction in any medium, provided the original author(s) and source are credited.

\section{References}

1. Breithardt, G., Kuhn, H., Hammel, D., Scheld, H. H., Seipel, L., \& Böcker, D. (2002). Cardiac resynchronization therapy into the next decade: From the past to morbidity/mortality trials. European Heart Journal Supplements, 4(Suppl D), D 102-D 110.

2. Bakker, P. F. A., Meijburg, H., de Jonge, N., van Mechelen, R., Wittkamp, F., Mower, M., et al. (1994). Beneficial effects of biventricular pacing in congestive heart failure. Pacing And Clinical Electrophysiology, 17(4), 820.

3. Cazeau, S., Ritter, P., Bakdach, S., Lazarus, A., Limousin, M., Henao, L., et al. (1994). Four chamber pacing in dilated cardiomyopathy. Pacing And Clinical Electrophysiology, 17(11 Pt 2), 1974-1979.

4. Bristow, M. R., Saxon, L. A., Boehmer, J., Krueger, S., Kass, D. A., De Marco, T., et al. (2004). Cardiac-resynchronization therapy with or without an implantable defibrillator in advanced chronic heart failure. The New England Journal of Medicine, 350(21), 2140-2150.

5. Cleland, J. G., Daubert, J. C., Erdmann, E., Freemantle, N., Gras, D., Kappenberger, L., et al. (2005). The effect of cardiac resynchronization on morbidity and mortality in heart failure. The New
England Journal of Medicine, 352(15), 1539-1549.

6. Abbasi, A. S., Eber, L. M., MacAlpin, R. N., \& Kattus, A. A. (1974). Paradoxical motion of interventricular septum in left bundle branch block. Circulation, 49(3), 423-427.

7. Curtius, J. M., Knuppel, S., Meschig, R., Balkenhoff, K., Arnold, G., \& Loogen, F. (1986). Course of left-ventricular contraction in left bundle-branch block and its hemodynamic effects. Zeitschrift für Kardiologie, 75(3), 138-146.

8. Curtius, J. M., Nowitzki, G., Kohler, E., Kuhn, H., \& Loogen, F. (1983). Left bundle-branch block: inferences from ventricular septal motion in the echocardiogram concerning left ventricular function. Zeitschrift für Kardiologie, 72(11), 635-641.

9. McDonald, I. G. (1973). Echocardiographic demonstration of abnormal motion of the interventricular septum in left bundle branch block. Circulation, 48, 272-280.

10. Fujii, J., Wantanabe, H., Watanabe, T., Takahashi, N., Ohta, A., \& Kato, K. (1979). M-mode and cross-sectional echocardiographic study of the left ventricular wall motions in complete left bundlebranch block. British Heart Journal, 42(3), 255-260.

11. van Oosterhout, M. F., Prinzen, F. W., Arts, T., Schreuder, J. J., Vanagt, W. Y., Cleutjens, J. P., et al. (1998). Asynchronous electrical activation induces asymmetrical hypertrophy of the left ventricular wall. Circulation, 98(6), 588-595.

12. van Oosterhout, M. F., Arts, T., Muijtjens, A. M., Reneman, R. S., \& Prinzen, F. W. (2001). Remodeling by ventricular pacing in hypertrophying dog hearts. Cardiovascular Research, 49(4), 771-778.

13. Dickstein, K., Vardas, P. E., Auricchio, A., Daubert, J. C., Linde, C., McMurray, J., et al. (2010). 2010 focused update of ESC Guidelines on device therapy in heart failure: An update of the 2008 ESC guidelines for the diagnosis and treatment of acute and chronic heart failure and the 2007 ESC guidelines for cardiac and resynchronization therapy. Developed with the special contribution of the Heart Failure Association and the European Heart Rhythm Association. European Journal of Heart Failure, 12(11), 1143-1153.

14. Jessup, M., Abraham, W. T., Casey, D. E., Feldman, A. M., Francis, G. S., Ganiats, T. G., et al. (2009). 2009 focused update: ACCF/AHA Guidelines for the Diagnosis and Management of Heart Failure in Adults: A report of the American College of Cardiology Foundation/American Heart Association Task Force on Practice Guidelines: Developed in collaboration with the International Society for Heart and Lung Transplantation. Circulation, 119(14), 1977-2016.

15. Zareba, W., Klein, H., Cygankiewicz, I., Hall, W. J., McNitt, S., Brown, M., et al. (2011). Effectiveness of cardiac resynchronization therapy by QRS morphology in the Multicenter Automatic Defibrillator Implantation Trial-Cardiac Resynchronization Therapy (MADIT-CRT). Circulation, 123(10), 1061-1072.

16. Bilchick, K. C., Kamath, S., DiMarco, J. P., \& Stukenborg, G. J. (2010). Bundle-branch block morphology and other predictors of outcome after cardiac resynchronization therapy in Medicare patients. Circulation, 122(20), 2022-2030.

17. Freedman, H. H. (1971). Ventricular conduction defects. In H. H. Freedman (Ed.), Diagnostic electrocardiography and vectorcardiography (pp. 163-192). New York: McGraw Hill.

18. Willems, J. L., Robles de Medina, E. O., Bernard, R., Coumel, P., Fisch, C., Krikler, D., et al. (1985). Criteria for intraventricular conduction disturbances and pre-excitation. World Health Organizational/International Society and Federation for Cardiology Task Force Ad Hoc. J Am Coll Cardiol, 5(6), 1261-1275.

19. Surawicz, B., Childers, R., Deal, B. J., Gettes, L. S., Bailey, J. J., Gorgels, A., et al. (2009). AHA/ACCF/HRS recommendations for the standardization and interpretation of the electrocardiogram: Part III: Intraventricular conduction disturbances: A scientific statement from the American Heart Association Electrocardiography and Arrhythmias Committee, Council on Clinical Cardiology; 
the American College of Cardiology Foundation; and the Heart Rhythm Society: Endorsed by the International Society for Computerized Electrocardiology. Circulation, 119(10), e235-e240.

20. Auricchio, A., Fantoni, C., Regoli, F., Carbucicchio, C., Goette, A., Geller, C., et al. (2004). Characterization of left ventricular activation in patients with heart failure and left bundle-branch block. Circulation, 109, 1133-1139.

21. Strauss, D. G., Selvester, R. H., \& Wagner, G. S. (2011). Defining left bundle branch block in the era of cardiac resynchronization therapy. The American Journal of Cardiology, 107(6), 927-934.

22. Strauss, D. G., \& Selvester, R. H. (2009). The QRS complex-a biomarker that "images" the heart: QRS scores to quantify myocardial scar in the presence of normal and abnormal ventricular conduction. Journal of Electrocardiology, 42(1), 85-96.

23. Macfarlane-P, L.-T. (1989). Appendix 1: Normal limits. In L.-T. Macfarlane-P (Ed.), Comprehensive electrocardiology. Theory and practice in health and disease (pp. 1441-1526). New York: Pergamon.

24. Seipel, L., Breithardt, G., \& Kuhn, H. (1978). Left bundle branch block in patients with and without cardiomyopathy. In M. Kaltenbach, F. Loogen, \& E. G. J. Olsen (Eds.), Cardiomyopathy and myocardial biopsy (pp. 237-250). Berlin: Springer.

25. Seipel, L., Breithardt, G., \& Kuhn, H. (1978). Significance of His bundle recording in bundle branch block. In H. J. T. Thalen \& J. W. Harthome (Eds.), To pace or not to pace. Controversial subjects on cardiac pacing (p. 3345). The Hague: Martinus Nijhoff Medical Division.

26. Amer, N. S., Stuckey, J. H., Hoffman, B. F., Cappelletti, R. R., \& Domingo, R. T. (1960). Activation of the interventricular septal myocardium studied during cardiopulmonary bypass. American Heart Journal, 59, 224-237.

27. Durrer, D., van Dam, R. T., Freud, G. E., Janse, M. J., Meijler, F. L., \& Arzbaecher, R. C. (1970). Total excitation of the isolated human heart. Circulation, 41(6), 899-912.

28. Rosen, K. M., Rahimtoola, S. H., Sinno, M. Z., \& Gunnar, R. M. (1971). Bundle branch and ventricular activation in man: A study using catheter recordings of left and right bundle branch potentials. Circulation, 43(2), 193-203.

29. Narula, O. S., Javier, R. P., Samet, P., \& Maramba, L. C. (1970). Significance of His and left bundle recordings from the left heart in man. Circulation, 42(3), 385-396.

30. Scheinman, M., Weiss, A., \& Kunkel, F. (1973). His bundle recordings in patients with bundle branch block and transient neurologic symptoms. Circulation, 48(2), 322-330.

31. Berkowitz, W. D., Lau, S. H., Patton, R. D., Rosen, K. M., \& Damato, A. N. (1971). The use of His bundle recordings in the analysis of unilateral and bilateral bundle branch block. American Heart Journal, 81(3), 340-350.

32. Fleischmann, D., Mathey, D., Bleifeld, W., Irnich, W., \& Effert, S. (1973). His bundle electrograms in patients with intraventricular conduction defects (author's transl). Klinische Wochenschrift, 21 (1), 1066-1073.

33. Vera, Z., Mason, D. T., Fletcher, R. D., Awan, N. A., \& Massumi, R. A. (1976). Prolonged His-Q interval in chronic bifascicular block. Relation to impending complete heart block. Circulation, 53(1), 47-55.

34. Cannom, D. S., Goodman, D. J., \& Harrison, D. C. (1974). Electrophysiological studies in patients with rate-related intermittent left bundle-branch block. British Heart Journal, 36(7), 653659.

35. Vassallo, J. A., Cassidy, D. M., Marchlinski, F. E., Buxton, A. E., Waxman, H. L., Doherty, J. U., et al. (1984). Endocardial activation of left bundle branch block. Circulation, 69(5), 914-923.

36. Vassallo, J. A., Cassidy, D. M., Miller, J. M., Buxton, A. E., Marchlinski, F. E., \& Josephson, M. E. (1986). Left ventricular endocardial activation during right ventricular pacing: effect of underlying heart disease. Journal of the American College of Cardiology, 7(6), 1228-1233.

37. Ansalone, G., Giannantoni, P., Ricci, R., Trambaiolo, P., Fedele, F., \& Santini, M. (2002). Doppler myocardial imaging to evaluate the effectiveness of pacing sites in patients receiving biventricular pacing. Journal of the American College of Cardiology, 39(3), 489-499.

38. Sogaard, P., Egeblad, H., Kim, W., Jensen, H., Pedersen, A., Kristensen, B., et al. (2002). Tissue Doppler imaging predicts improved systolic performance and reversed left ventricular remodeling during long-term cardiac resynchronization therapy. Journal of the American College of Cardiology, 40(4), 723-730.

39. Becker, M., Franke, A., Breithardt, O. A., Kaminski, T., Kramann, R., Knackstedt, C., et al. (2007). Impact of left ventricular lead position on the efficacy of cardiac resynchronization therapy. A two-dimensional strain echocardiography study. Heart, 93(10), 1197-1203.

40. Becker, M., Hoffmann, R., Schmitz, F., Hundemer, A., Kuhl, H., Schauerte, P., et al. (2007). Relation of optimal lead positioning as defined by three-dimensional echocardiography to long-term benefit of cardiac resynchronization. The American Journal of Cardiology, 100(11), 1671-1676.

41. Smith, S., \& Hayes, W. L. (1965). The prognosis of complete left bundle branch block. American Heart Journal, 70, 157-159.

42. Messer, A. L., Johnson, R. P., Shreenivas, \& White, P. D. (1951). Prognosis in bundle branch block. II. A comparison of right and left bundle branch block with a note on the relative incidence of each. American Heart Journal, 41(2), 239-245.

43. Rodstein, M., Gubner, R., Mills, J. P., Lovell, J. F., \& Ungerleider, H. E. (1951). A mortality study in bundle branch block. $A M A$ Archives of Internal Medicine, 87(5), 663-668.

44. Rotman, M., \& Triebwasser, J. H. (1975). A clinical and follow-up study of right and left bundle branch block. Circulation, 51(3), 477-484.

45. Smith, R. F., Jackson, D. H., Harthorne, J. W., \& Sanders, C. A. (1970). Acquired bundle branch block in a healthy population. American Heart Journal, 80(6), 746-751.

46. Kuhn, H., Breithardt, G., Knieriem, H. J., Kohler, E., Losse, B., Seipel, L., et al. (1978). Prognosis and possible presymptomatic manifestations of congestive cardiomyopathy (COCM). Postgraduate Medical Journal, 54(633), 451-461.

47. Kuhn, H., Breithardt, L. K., Breithardt, G., Seipel, L., \& Loogen, F. (1974). Die Bedeutung des Elektrokardiogramms für die Diagnose und Verlaufsbeobachtung von Patienten mit kongestiver Kardiomyopathie. Zeitschrift für Kardiologie, 63, 916-927.

48. Blondeau, M. (1974). Complete left branch block with strong left axial deviation of the QRS. I. Clinical study. Archives des Maladies du Coeur et des Vaisseaux, 67(6), 662-734.

49. Schneider, J. F., Thomas, H. E., Jr., Kreger, B. E., McNamara, P. M., \& Kannel, W. B. (1979). Newly acquired left bundle-branch block: The Framingham study. Annals of Internal Medicine, 90(3), 303-310.

50. Johnson, R. P., Messer, A. L., \& Shreenivas. (1951). The significance of bundle-branch block. Texas State Journal of Medicine, 47 (9), 621-626.

51. Marchandise, B., Piette, F., Chalant, C. H., \& Kremer, R. (1975). Conduction disorders in aortic valve diseases. Acta Cardiologica, 30(2), 111-128.

52. Wilensky, R. L., Yudelman, P., Cohen, A. I., Fletcher, R. D., Atkinson, J., Virmani, R., et al. (1988). Serial electrocardiographic changes in idiopathic dilated cardiomyopathy confirmed at necropsy. The American Journal of Cardiology, 62(4), 276-283.

53. Stewart, R. A., Young, A. A., Anderson, C., Teo, K. K., Jennings, G., \& Cowan, B. R. (2011). Relationship between QRS duration and left ventricular mass and volume in patients at high cardiovascular risk. Heart, 97(21), 1766-1770. 
54. Kashani, A., \& Barold, S. S. (2005). Significance of QRS complex duration in patients with heart failure. Journal of the American College of Cardiology, 46(12), 2183-2192.

55. Xiao, H. B., Roy, C., Fujimoto, S., \& Gibson, D. G. (1996). Natural history of abnormal conduction and its relation to prognosis in patients with dilated cardiomyopathy. International Journal of Cardiology, 53(2), 163-170.

56. Grigioni, F., Carinci, V., Boriani, G., Bracchetti, G., Potena, L., Magnani, G., et al. (2002). Accelerated QRS widening as an independent predictor of cardiac death or of the need for heart transplantation in patients with congestive heart failure. The Journal of Heart and Lung Transplantation, 21(8), 899-902.

57. Van Garsse, L. A., Houthuizen, P., Poels, T. T., Swinkels, B. M., ten Berg, J. M., van der Kley, F., et al. (2011). Left bundle branch block induced by transcatheter aortic valve implantation increases risk for 1-year all-cause mortality (Abstract). Circulation, 124, A11770.

58. Takeshita, A., Basta, L. L., \& Kioschos, J. M. (1974). Effect of intermittent left bundle branch block on left ventricular performance. American Journal of Medicine, 56(2), 251-255.

59. Das, M. K., Cheriparambil, K., Bedi, A., Kassotis, J., Es, D., Reddy, C. V., et al. (2001). Prolonged QRS duration (QRS $>/=170 \mathrm{~ms})$ and left axis deviation in the presence of left bundle branch block: A marker of poor left ventricular systolic function? American Heart Journal, 142(5), 756-759.

60. Verbeek, X. A., Vernooy, K., Peschar, M., Van Der, N. T., Van Hunnik, A., \& Prinzen, F. W. (2002). Quantification of interventricular asynchrony during LBBB and ventricular pacing. American Journal of Physiology-Heart and Circulatory Physiology, 283(4), H1370-H1378.

61. Kuhn, H., Lösse, B., \& Hart, W. (1982). Studies in patients with abnormal electrocardiogram of unknown etiology. In H. Tillmanns, W. Kübler, \& H. Zebe (Eds.), Microcirculation of the heart (pp. 288-295). Berlin: Springer.

62. Erlebacher, J. A., \& Barbarash, S. (2001). Intraventricular conduction delay and functional mitral regurgitation. The American Journal of Cardiology, 88(1), 83-86.

63. Godley, R. W., Wann, L. S., Rogers, E. W., Feigenbaum, H., \& Weyman, A. E. (1981). Incomplete mitral leaflet closure in patients with papillary muscle dysfunction. Circulation, 63(3), 565-571.

64. Kono, T., Sabbah, H. N., Rosman, H., Alam, M., Jafri, S., Stein, P. D., et al. (1992). Mechanism of functional mitral regurgitation during acute myocardial ischemia. Journal of the American College of Cardiology, 19(5), 1101-1105.

65. Ogawa, S., Hubbard, F. E., Mardelli, T. J., \& Dreifus, L. S. (1979). Cross-sectional echocardiographic spectrum of papillary muscle dysfunction. American Heart Journal, 97(3), 312-321.

66. Otsuji, Y., Handschumacher, M. D., Liel-Cohen, N., Tanabe, H., Jiang, L., Schwammenthal, E., et al. (2001). Mechanism of ischemic mitral regurgitation with segmental left ventricular dysfunction: Three-dimensional echocardiographic studies in models of acute and chronic progressive regurgitation. Journal of the American College of Cardiology, 37(2), 641-648.

67. Nowak, B., Stellbrink, C., Schaefer, W. M., Sinha, A. M., Breithardt, O. A., Kaiser, H. J., et al. (2004). Comparison of regional myocardial blood flow and perfusion in dilated cardiomyopathy and left bundle branch block: Role of wall thickening. Journal of Nuclear Medicine, 45(3), 414-418.

68. DePuey, E. G., Guertler-Krawczynska, E., \& Robbins, W. L. (1988). Thallium-201 SPECT in coronary artery disease patients with left bundle branch block. Journal of Nuclear Medicine, 29(9), $1479-1485$

69. Hirzel, H. O., Senn, M., Nuesch, K., Buettner, C., Pfeiffer, A., Hess, O. M., et al. (1984). Thallium-201 scintigraphy in complete left bundle branch block. The American Journal of Cardiology, 53 (6), 764-769.

70. Vernooy, K., Verbeek, X. A., Peschar, M., Crijns, H. J., Arts, T., Cornelussen, R. N., et al. (2005). Left bundle branch block induces ventricular remodelling and functional septal hypoperfusion. European Heart Journal, 26(1), 91-98.

71. Wackers, F. J. T., Soufer, R., \& Zaret, B. L. (2001). Nuclear cardiology. In E. Braunwald, D. P. Zipes, \& P. Libby (Eds.), Heart disease (p. 295). Philadelphia: Saunders.

72. Frenzel, H., Kasper, M., Kuhn, H., Losse, B., Reifschneider, G., \& Hort, W. (1985). Light and electron microscopy findings in early and late stages of heart failure. Studies of endomyocardial biopsies of patients with latent (LCM) and dilated (DCM) cardiomyopathy. Zeitschrift für Kardiologie, 74(3), 135-143.

73. Kuhn, H., Breithardt, G., Knieriem, H. J., \& Loogen, F. (1978). Endomyocardial catheter biopsy in heart disease of unknown etiology. In M. Kaltenbach, F. Loogen, \& E. G. J. Olsen (Eds.), Cardiomyopathy and myocardial biopsy (pp. 121-137). Berlin: Springer.

74. Curtius, J. M., Stechern, V., Kuhn, H., \& Loogen, F. (1984). Echocardiographic follow-up in latent cardiomyopathy. Zeitschrift für Kardiologie, 73(11), 695-700.

75. Lamas, G. A., Lee, K. L., Sweeney, M. O., Silverman, R., Leon, A., Yee, R., et al. (2002). Ventricular pacing or dual-chamber pacing for sinus-node dysfunction. The New England Journal of Medicine, 346(24), 1854-1862.

76. Wilkoff, B. L., Cook, J. R., Epstein, A. E., Greene, H. L., Hallstrom, A. P., Hsia, H., et al. (2002). Dual-chamber pacing or ventricular backup pacing in patients with an implantable defibrillator: The Dual Chamber and VVI Implantable Defibrillator (DAVID) Trial. Journal of the American Medical Association, 288 (24), 3115-3123.

77. Barsheshet, A., Moss, A. J., McNitt, S., Jons, C., Glikson, M., Klein, H. U., et al. (2011). Long-term implications of cumulative right ventricular pacing among patients with an implantable cardioverter-defibrillator. Heart Rhythm, 8(2), 212-218.

78. Curtius, J. M., Freimuth, M., Kuhn, H., Kohler, E., \& Loogen, F. (1982). Exercise echocardiography in dilatative cardiomyopathy. Zeitschrift für Kardiologie, 71(11), 727-735.

79. Breithardt, O. A., Sinha, A. M., Schwammenthal, E., Bidaoui, N., Markus, K. U., Franke, A., et al. (2003). Acute effects of cardiac resynchronization therapy on functional mitral regurgitation in advanced systolic heart failure. Journal of the American College of Cardiology, 41(5), 765-770.

80. Xiao, H. B., Lee, C. H., \& Gibson, D. G. (1991). Effect of left bundle branch block on diastolic function in dilated cardiomyopathy. British Heart Journal, 66(6), 443-447. 